\title{
Optical coherence tomography assessment of the acute effects of stent implantation on the vessel wall: a systematic quantitative approach
}

\author{
N Gonzalo, P W Serruys, T Okamura, Z J Shen, Y Onuma, H M Garcia-Garcia, G Sarno, \\ C Schultz, R J van Geuns, J Ligthart, E Regar
}

\section{See Editorial, p 1895}

Thoraxcenter, Erasmus MC, Erasmus University, Rotterdam, The Netherlands

Correspondence to: Dr E Regar, Thoraxcenter, Erasmus MC, Bd 585, 's-Gravendijkwal 230, 3015-CE Rotterdam, The Netherlands; e.regar@erasmusmc.nl

Accepted 28 July 2009 Published Online First 10 August 2009

\begin{abstract}
Objective: To observe and characterise vessel injury after stenting using optical coherence tomography (OCT), to propose a systematic OCT classification for periprocedural vessel trauma, to evaluate its frequency in stable versus unstable patients and to assess its clinical impact during the hospitalisation period.
\end{abstract}

Setting: Stenting causes vessel injury.

Design and interventions: All consecutive patients in whom OCT was performed after stent implantation were included in the study. Qualitative and quantitative assessment of tissue prolapse, intra-stent dissection and edge dissection were performed.

Results: Seventy-three patients (80 vessels) were analysed. Tissue prolapse within the stented segment was visible in 78/80 vessels (97.5\%). Median number of tissue prolapse sites was 8 (IOR 4-19), mean (SD) area $1.04(0.9) \mathrm{mm}^{2}$. Intra-stent dissection flaps were visible in 69/80 vessels (86.3\%) (median number 3 (IOR 1.25-6), maximum flap length $450(220) \mu \mathrm{m})$. Fifty-five out of 80 vessels (68.8\%) showed dissection cavities (median number 2 (IOR 0-4.75), maximum depth 340 (170) $\mu \mathrm{m}$ ). Edge dissection was visible in 20 vessels (mean (SD) length flap $744(439) \mu \mathrm{m})$. The frequency of tissue prolapse or intra-stent dissection was similar in stable and unstable patients $(95.6 \%$ vs $100 \%, p=0.5$ for tissue prolapse; $91.1 \%$ vs $82.9 \%, p=0.3$ for intra-stent dissection). There were no events during the hospitalisation period.

Conclusions: OCT allows a detailed visualisation of vessel injury after stent implantation and enables a systematic classification and quantification in vivo. In this study, frequency of tissue prolapse or intra-stent dissections after stenting was high, irrespective of the clinical presentation of the patients, and was not associated with clinical events during hospitalisation.

Coronary stent implantation generally creates a certain degree of injury on the vessel wall. Pathological studies have demonstrated plaque compression by the stent and penetration of the struts into the underlying plaque. ${ }^{1}$ High-pressure stenting techniques have proved to be useful for an optimal stent implantation in order to reduce the risk of restenosis and subacute thrombosis. However, this stent deployment strategy may also increase the risk of vessel damage in the stented segment or at the edges. ${ }^{2}$

Optical coherence tomography (OCT) is a highresolution imaging technique which allows a detailed assessment of the anatomical relation between the stent and the vessel wall. ${ }^{34}$ As a consequence, various degrees of vessel injury after stent implantation are frequently detected with this technique even when they are not visible by cine-angiography or intravascular ultrasound. The different types of acute vessel damage caused by stenting that can be seen by OCT and their frequency in different clinical scenarios have not been described yet. Furthermore, the clinical implications of these OCT findings are not well established.

The objectives of this study were to observe and characterise vessel injury after stenting using OCT, to propose a systematic OCT classification for periprocedural vessel trauma, to evaluate its incidence in stable versus unstable (unstable angina IB/IIB/IIIB Braunwald classification and ST elevation myocardial infarction (MI)) patients and to assess its clinical impact during the hospitalisation period.

\section{PATIENTS AND METHODS}

\section{Study population}

All consecutive patients in whom OCT was performed after stent implantation between January 2007 and December 2008 were included in the study. All patients gave informed consent.

\section{OCT acquisition}

The OCT acquisition was performed using a commercially available system for intracoronary imaging (LightLab Imaging, Westford, Massachusetts, USA). The ImageWire (LightLab Imaging) consists of an optical fibre core $(125 \mu \mathrm{m})$ covered by a protective sheath with a maximum outer diameter of $0.019^{\prime \prime}$. The acquisition technique has been previously described. ${ }^{5}$ In seven cases the occlusive technique was used, in which a proximal, low-pressure (0.4 atm) occlusion balloon (Helios, Goodman, Nagoya, Japan) is inflated with simultaneous distal flush delivery (lactated ringer; flow rate $0.8 \mathrm{ml} / \mathrm{s}$ ) to remove blood from the vessel lumen. Images were acquired during a pullback rate of $1.0 \mathrm{~mm} / \mathrm{s}$. In 73 cases OCT was acquired with the non-occlusive technique. In this case, the ImageWire was positioned distal to the region of interest using a double lumen catheter (Twin Pass catheter; Vascular Solutions, Minneapolis, USA) that had been previously placed in the artery over a conventional guide wire. The automated pullback was performed at $3 \mathrm{~mm} / \mathrm{s}$ while the blood was removed by the continuous injection of isoosmolar contrast (Iodixanol 370; VisipaqueGE 


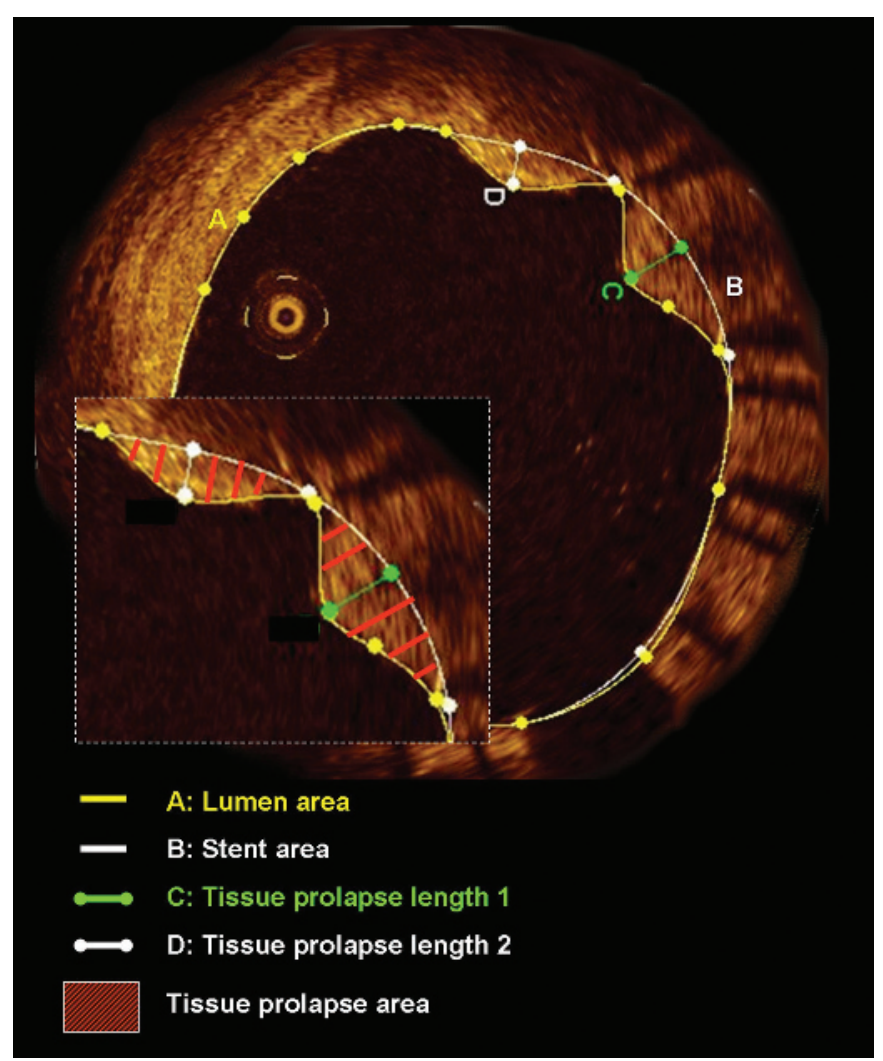

Figure 1 Tissue prolapse: defined as convex shaped, protrusion of tissue between adjacent stent struts towards the lumen without disruption of the continuity of the luminal vessel surface. The figure shows a cross section in which tissue prolapse is visible. The amplified image shows two areas of tissue prolapse. For each tissue prolapse region the maximum length and the area were measured.

Health Care, Ireland) at $37^{\circ} \mathrm{C}$ through the guiding catheter. The data was stored on CD for offline analysis.

\section{Definitions of acute effects of stent implantation in OCT}

Analysis encompassed the intra-stent segment, defined by the first and the last cross section with a visible strut, and the adjacent vessel segments $5 \mathrm{~mm}$ proximal and distal to the stent (edge segments).

- Tissue prolapse: convex-shaped, protrusion of tissue between adjacent stent struts towards the lumen, without disruption of the continuity of the luminal vessel surface (fig 1). Protrusion of tissue between struts was considered tissue prolapse only if the distance from the arc connecting adjacent stent struts to the greatest extent of protrusion was $>50 \mu \mathrm{m}$.

- Intra-stent dissection: disruption of the luminal vessel surface in the stent segment. It can appear in two forms: (a) dissection: the vessel surface is disrupted and a dissection flap is visible; (b) cavity: the vessel surface is disrupted and an empty cavity can be seen (fig 2).

- Edge dissection: disruption of the luminal vessel surface in the edge segments (within $5 \mathrm{~mm}$ proximal and distal to the stent, no struts are visible) (fig 3).

- Thrombus: irregular mass with dorsal shadowing protruding in the lumen (mural thrombus) or a luminal mass with dorsal shadowing that is not connected to the vessel wall (fig 4).

\section{Quantitative OCT analysis of the acute effects of stent implantation}

The analysed region comprised the intra-stent and edge segments. The lumen and stent area were measured in $1 \mathrm{~mm}$ intervals along the pullbacks. In the proximal and distal edge segments, the lumen area was measured. In cases of tissue prolapse the number of sites with tissue prolapse was counted. Tissue prolapse length was defined as the distance from the arc connecting adjacent stent struts to the greatest extent of protrusion (the maximum and average tissue prolapse length were calculated). The area of tissue protruding between the stent struts was also measured (tissue prolapse area) (fig 1). When there were signs of intra-stent dissection the number of dissection flaps or cavities was counted and the length of the flap (from its tip to the joint point with the vessel wall) or the maximum depth of the cavity (from the lumen to the deepest cavity point inside the vessel wall) was measured (fig 2). When edge dissection was present the length of the dissection flap (in a similar way as described for intra-stent dissection flap) was

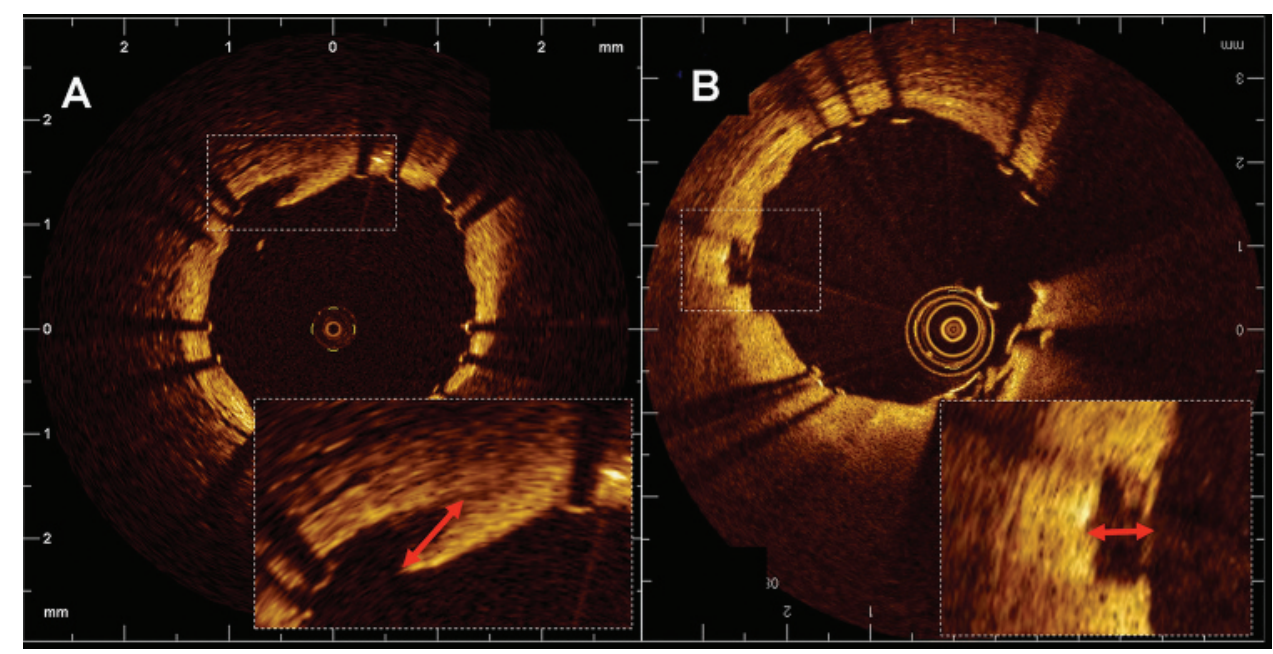

Figure 2 Intra-stent dissection: defined as a disruption of the vessel luminal surface in the stent segment. This entity can appear with two forms: (A) dissection: the vessel surface is disrupted and a dissection flap is visible. The length of the flap (red arrow) was measured as the distance from its tip to the joint point with the vessel wall; $(B)$ cavity: the vessel surface is disrupted and an empty cavity can be seen. The maximum depth of the cavity (red arrow) was measured from the lumen to the deepest cavity point inside the vessel wall. 


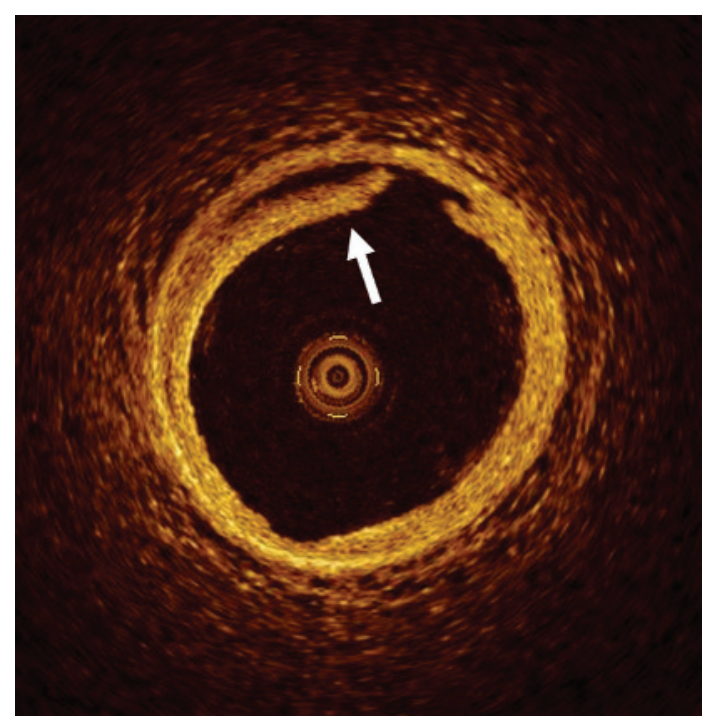

Figure 3 Edge dissection: defined as a disruption of the vessel luminal surface in the edge region $(5 \mathrm{~mm}$ proximal and distal to the stented region, no struts are visible).

measured. The presence of thrombus was qualitatively assessed and the number of frames with visible thrombus was recorded. When incomplete stent apposition (defined as separation of at least one stent strut from the vessel wall not related with a side branch) was visible, the maximum distance from the endoluminal surface of the strut to the vessel wall was measured (maximum incomplete stent apposition length) To take into account differences in the stent length, the number of tissue prolapse sites, number of dissection flaps and number of cavities were normalised by the stent length and expressed per $\mathrm{mm}$.

The analysts were blinded to the clinical and procedural characteristics.

\section{Clinical follow-up}

The presence of events (death, MI, target lesion revascularisation, target vessel revascularisation and stent thrombosis) during the hospitalisation period following stent implantation was registered. MI included reinfarction (defined as recurrence of symptoms together with ST elevation or new left bundle branch block and an increase in cardiac enzymes following stable or decreasing values) or spontaneous MI (diagnosed by a rise in creatine kinase- $\mathrm{MB}$ fraction of three times the upper limit of normal together with symptoms and either new ST elevation or left bundle branch block).

\section{Statistical analysis}

Continuous variables are expressed as mean (SD) or median and interquartile range. Categorical variables are expressed as percentages. Comparisons between groups were performed with $\chi^{2}$ for categorical variables. Continuous variables were compared with the Student $t$ test when they had a normal distribution and with a non-parametric test (Mann-Whitney) when their distribution was not normal.

\section{RESULTS}

\section{Clinical and procedural characteristics}

Seventy-three patients, 80 vessels were included in the study. Table 1 shows the clinical and procedural characteristics.

\section{Acute effects of stent implantation assessed by OCT}

The mean (SD) lumen area measured by OCT was 7.16 (1.7) $\mathrm{mm}^{2}$. The minimum lumen area in-stent was 5.65 (1.7) $\mathrm{mm}^{2}$. The mean and minimum stent areas were 7.40 (1.9) and $5.70(1.76) \mathrm{mm}^{2}$, respectively.

Fifty-one out of the 80 vessels (63.8\%) showed at least one malapposed strut and the average maximum incomplete stent apposition length was 281 (145) $\mu \mathrm{m}$. Findings suggestive of thrombus were visible in $36 / 80$ vessels (45\%). The median number of frames with visible thrombus was 0 (IOR $0-1$ ) and the median number of frames with thrombus normalised by the stent length was 0 (IOR 0-0.06).

\section{Tissue prolapse}

Table 2 shows the frequency and quantitative assessment of tissue prolapse as assessed by OCT.

\section{Intra-stent dissection}

Table 2 presents the frequency and quantitative measurements of intra-stent dissection as assessed by OCT.

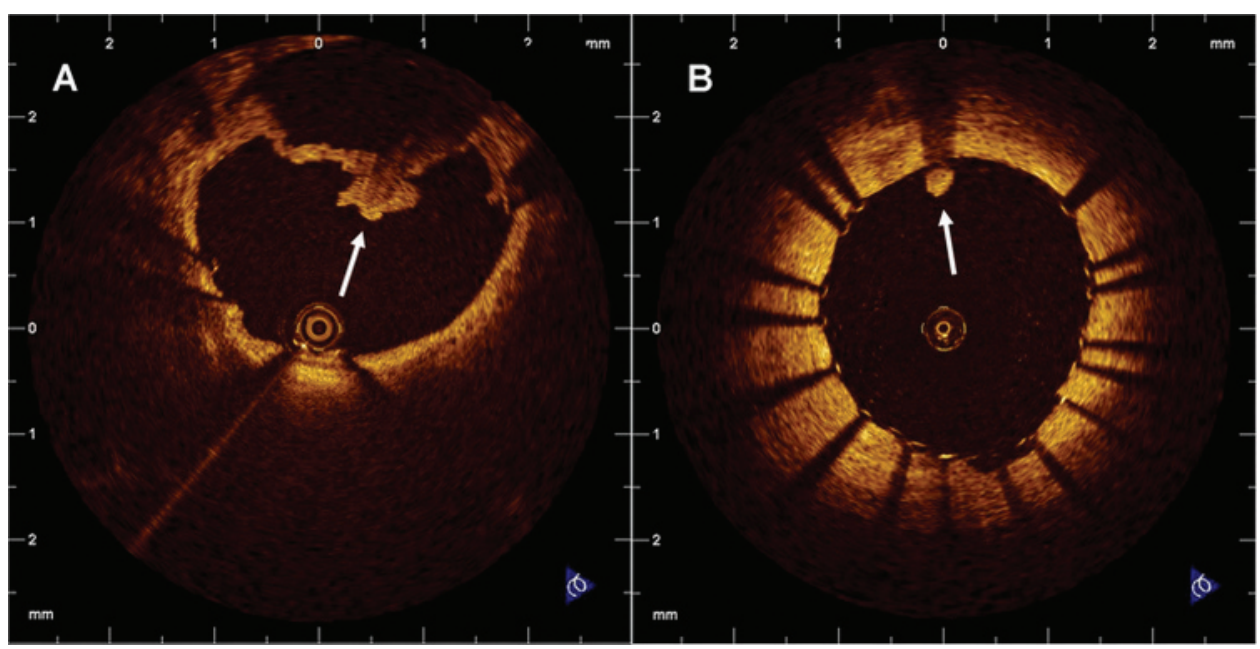

Figure 4 Thrombus: defined as an irregular mass with dorsal shadowing protruding in the lumen (mural thrombus) (white arrow in A) or a luminal mass with dorsal shadowing that is not connected to the vessel wall (white arrow in B). 
Table 1 Baseline clinical and procedural characteristics

\begin{tabular}{lc}
\hline Clinical characteristics ( $\mathbf{n}=\mathbf{7 3}$ patients) & \\
Demographics & \\
Age (years), mean (SD) & $62(10)$ \\
Male (\%) & $57(78.1)$ \\
HT (\%) & $44(60.3)$ \\
DM (\%) & $14(19.2)$ \\
Dyslipidaemia (\%) & $46(63)$ \\
Smoker (\%) & $22(30.1)$ \\
Family history (\%) & $25(34.2)$ \\
Cardiac history & \\
Previous MI (\%) & $28(38.4)$ \\
Previous CABG (\%) & $2(2.7)$ \\
Previous PCI (\%) & $27(37)$ \\
Clinical presentation & \\
Stable angina (\%) & $41(56.2)$ \\
Unstable angina (\%) & $22(30.1)$ \\
STEMI (\%) & $10(13.7)$ \\
Procedural characteristics (n= 80 vessels) & \\
Vessel & \\
LAD (\%) & \\
LCX (\%) & $41(51.3)$ \\
RCA (\%) & $12(15)$ \\
Stent type & $27(33.8)$ \\
BMS (\%) & \\
Paclitaxel-eluting stent (\%) & $14(17.5)$ \\
Sirolimus-eluting stent (\%) & $5(6.3)$ \\
Everolimus-eluting stent (\%) & $4(5)$ \\
Zotarolimus-eluting stent (\%) & $44(55)$ \\
Tacrolimus-eluting stent (\%) & $12(15)$ \\
Other data & $1(1.3)$ \\
Number of stents, mean (SD) & \\
Stent diameter, mean (SD) & $1.6(0.8)$ \\
Stent length, mean (SD) & $39(4.3)$ \\
Implantation pressure, mean (SD) & \\
Predilatation & \\
Postdilatation & \\
Rotational atherectomy & \\
Thrombectomy & \\
\hline Results are shown as number (\%) unless stated otherwise. \\
BMS, bare metal stent; CABG, coronary artery bypass graft surgery; \\
DM, diabetes mellitus; HT, hypertension; LAD, left anterior descending \\
coronary artery; LCX, left circumflex artery; MI, myocardial infarction; \\
PCl, percutaneous coronary intervention; RCA, right coronary artery; \\
STEMl, ST elevation myocardial infarction. \\
\end{tabular}

Edge dissection

In four cases edge regions were not visible. Twenty vessels out of 76 showed edge dissection. Four vessels showed both proximal and distal edge dissection. The mean (SD) length of the dissection flap was $744(439) \mu \mathrm{m}$.

\section{Acute effects of stent implantation as assessed by OCT in relation to the clinical presentation}

The effects of stent implantation in the vessel as assessed by OCT were compared in stable versus unstable (unstable angina IB/IIB/IIIB Braunwald classification and ST elevation MI) patients. Table 3 shows the baseline clinical and procedural characteristics of the two groups.

The frequency of incomplete stent apposition was not different between groups $(27 / 45(60 \%)$ for stable vs $24 / 34$ $(70.6 \%)$ for unstable $p=0.3)$. The maximum incomplete stent apposition length was 280 (74) $\mu \mathrm{m}$ for stable and 283 (198) $\mu \mathrm{m}$ for unstable patients $(p=0.9)$. Structures suggestive of thrombus were visible in $20 / 45(44.4 \%)$ stable patients vs $16 / 35$
Table 2 Tissue prolapse, intra-stent dissection, edge dissection frequency and quantitative optical coherence tomography assessment

Tissue prolapse

Tissue prolapse visible, $\mathrm{n}(\%)$

78 (97.5)

Number of sites of tissue prolapse, median (IQR)

8 (4-19)

Number of sites of tissue prolapse per mm, median (IOR)

Tissue prolapse area $\left(\mathrm{mm}^{2}\right)$, mean (SD)

$0.3(0.17-0.69)$

$1.04(0.9)$

Tissue prolapse area per $\mathrm{mm}\left(\mathrm{mm}^{2}\right)$, mean (SD)

Tissue prolapse average length $(\mu \mathrm{m})$, mean (SD)

Tissue prolapse maximum length $(\mu \mathrm{m})$, mean (SD)

$0.03(0.03)$

Intra-stent dissection

Intra-stent dissection visible, $\mathrm{n}(\%)$

151 (42)

254 (90)

Intra-stent dissection flap

Intra-stent dissection flap visible, n (\%)

70 (87.5)

Number intra-stent dissection flaps, median (IOR)

$69(86.3)$

$3(1.25-6)$

Number intra-stent dissection flaps per mm, median (IOR)

$0.10(0.05-0.22)$

Intra-stent dissection flap average length $(\mu \mathrm{m})$, mean (SD) 300 (130)

Intra-stent dissection flap maximum length $(\mu \mathrm{m})$, mean (SD) 450 (220)

Intra-stent dissection cavity

Intra-stent dissection cavity visible, n (\%) 55 (68.8)

Number cavities, median (IOR)

$2(0-4.75)$

Number cavities per mm, median (IOR)

Maximum depth cavity $(\mu \mathrm{m})$, mean (SD)

$0.07(0-0.16)$

Edge dissection

Edge dissection visible, $\mathrm{n}(\%)$

340 (170)

Length edge dissection flap, mean (SD)

20/76 (26.3)

744 (439)

$(45.7 \%)$ unstable patients $(p=0.9)$. There were also no significant differences in the median number of frames with visible thrombus between stable 0 (IOR $0-1$ ) and unstable 0 (IOR $0-2)$ patients $(p=0.9)$. The median number of frames with visible thrombus normalised by the stent length was 0 (IOR 0-0.05) for stable and 0 (IOR 0-0.08) for unstable $(p=0.7)$. Table 4 shows the frequency and quantitative assessment of tissue prolapse, intra-stent dissections and edge dissections in patients with stable versus unstable clinical presentation.

\section{In-hospital events}

There were no events (death, MI, target lesion revascularisation, target vessel revascularisation or stent thrombosis) during the hospitalisation period.

\section{DISCUSSION}

This study proposes a systematic classification and quantification of a variety of acute effects of stent implantation on the vessel wall, as visible by OCT. The main findings are: (a) OCT allows for a detailed visualisation of periprocedural vessel wall trauma in coronary stenting and enables a systematic classification and quantification in vivo; $(b)$ a very high proportion of patients, irrespective of their clinical presentation, showed tissue prolapse or intra-stent dissections visible by OCT after stent implantation, but this finding was not associated with clinical events during hospitalisation.

\section{OCT for the detection of vessel injury after stenting}

OCT is a light-based technique which can provide in vivo imaging of the coronary artery with near-histological resolution. This technique has opened new possibilities for the evaluation of stents at follow-up, allowing a very detailed assessment of strut apposition and tissue coverage..$^{8-12}$ This study demonstrates its ability to detect and distinguish different types of 
Table 3 Clinical and procedural characteristics of stable versus unstable patients

\begin{tabular}{|c|c|c|c|}
\hline Characteristics & Stable & Unstable & p Value \\
\hline \multicolumn{4}{|l|}{ Demographics } \\
\hline Age, mean (SD) & $62.3(9.9)$ & $61.7(10.4)$ & 0.8 \\
\hline Male (\%) & $34 / 41(82.9)$ & 23/32 (71.9) & 0.1 \\
\hline HT (\%) & $25 / 41(61)$ & 19/32 (59.4) & 0.8 \\
\hline DM (\%) & $8 / 41(19.5)$ & 6/32 (18.8) & 0.9 \\
\hline Dyslipidaemia (\%) & $30 / 41(73.2)$ & $16 / 32(50)$ & 0.05 \\
\hline Smoker (\%) & $10 / 41(24.4)$ & $12 / 32(37.5)$ & 0.3 \\
\hline Family history (\%) & $16 / 41(39)$ & $9 / 32(28.1)$ & 0.2 \\
\hline \multicolumn{4}{|l|}{ Cardiac history } \\
\hline Previous myocardial infarction (\%) & 18/41 (43.9) & 10/32 (31.3) & 0.3 \\
\hline Previous CABG (\%) & $1 / 41(2.4)$ & $1 / 32(3.1)$ & 1 \\
\hline Previous PCI (\%) & $16 / 41$ (39) & $11 / 32(34.4)$ & 0.8 \\
\hline \multicolumn{4}{|l|}{ Vessel } \\
\hline LAD (\%) & $22 / 45(48.9)$ & $19 / 35(54.3)$ & \\
\hline LCX (\%) & $8 / 45(17.8)$ & 4/35 (11.4) & 0.8 \\
\hline RCA (\%) & $15 / 45(33.3)$ & $12 / 35(34.3)$ & \\
\hline \multicolumn{4}{|l|}{ Stent type } \\
\hline BMS (\%) & $11 / 45(24.4)$ & $3 / 35(8.6)$ & 0.08 \\
\hline Paclitaxel-eluting stent (\%) & $5 / 45(11.1)$ & 0 & \\
\hline Sirolimus-eluting stent (\%) & $1 / 45(2.2)$ & $3 / 35(8.6)$ & \\
\hline Everolimus-eluting stent (\%) & $19 / 45(42.2)$ & 25/35 (71.4) & \\
\hline Zotarolimus-eluting stent (\%) & $8 / 45(17.8)$ & $4 / 35(11.4)$ & \\
\hline Tacrolimus-eluting stent (\%) & $1 / 45(2.2)$ & 0 & \\
\hline \multicolumn{4}{|l|}{ Other data } \\
\hline Number of stents, mean (SD) & $1.5(0.8)$ & $1.8(0.8)$ & 0.2 \\
\hline Stent diameter $(\mathrm{mm})$, mean $(\mathrm{SD})$ & $3.0(0.5)$ & $3(0.3)$ & 0.7 \\
\hline Stent length (mm), mean (SD) & $33(17)$ & $35(17)$ & 0.5 \\
\hline $\begin{array}{l}\text { Implantation pressure (atm), mean } \\
\text { (SD) }\end{array}$ & $17(4)$ & $17(3)$ & 0.7 \\
\hline Predilatation (\%) & $25 / 45(55.6)$ & $14 / 35(40)$ & 0.2 \\
\hline Postdilatation (\%) & $21 / 45(46.7)$ & $13 / 35(37.1)$ & 0.4 \\
\hline Rotational atherectomy (\%) & $1 / 45(2.2)$ & 0 & 1 \\
\hline
\end{tabular}

Results are shown as number (\%) unless stated otherwise. $\mathrm{BMS}$, bare metal stent; $\mathrm{CABG}$, coronary artery bypass graft surgery; DM, diabetes mellitus; $H T$, hypertension; $L A D$, left anterior descending coronary artery; LCX, left circumflex artery; $\mathrm{PCl}$, percutaneous coronary intervention; RCA, right coronary artery.

vessel injury during stent implantation. Furthermore, OCT allows not only qualitative but also quantitative evaluation of the acute effects of stenting in vivo. Previous reports have shown that OCT can also visualise vascular effects of other coronary devices such as balloon-induced dissections and cuts made by the blades of a cutting balloon. ${ }^{13}$ Furthermore, OCT has proved to be useful for the evaluation of strut symmetry or the presence of intracoronary thrombus after stenting. ${ }^{14-16}$

\section{Tissue prolapse after stenting}

In a postmortem study, compression of the coronary plaque after stent implantation with protrusion of tissue between the struts was seen in $94 \%$ of the patients. ${ }^{1}$ This is in agreement with our study in which tissue prolapse between the struts was visible in the vast majority of patients. It is in contrast to intravascular ultrasound (IVUS) studies, which have reported a relatively low plaque prolapse incidence ranging from 18\% to $35 \% .{ }^{17}$ The higher sensitivity of OCT in comparison with IVUS for the detection of this phenomenon has been previously published. ${ }^{78}$ The clinical impact of the presence of tissue prolapse after stenting, however, is not well established. An IVUS study demonstrated a correlation between creatine kinase- $\mathrm{MB}$ elevation post-procedure and the extent of plaque prolapse. ${ }^{17}$ However, IVUS has failed to show differences in the rate of stent thrombosis or stent restenosis between patients with and without plaque prolapse. ${ }^{19}{ }^{20}$ In our study, even when almost all patients had visible tissue prolapse by OCT, no clinical events during hospitalisation occurred. Therefore, nonflow-limiting tissue prolapse as visualised by OCT in our study appears to be a benign phenomenon in the short term that might not require further treatment.

\section{Intra-stent and edge dissections}

OCT allows the visualisation of the disruption of the endoluminal vessel wall continuity in the intra-stent segment and it can distinguish between the presence of a flap or a region with loss of material (cavity). IVUS (with an axial resolution of around $150 \mu \mathrm{m}$ ) is hampered in distinguishing intra-stent dissections from plaque prolapse. However, by OCT those two entities can be clearly differentiated and might have different clinical implications. In our series, despite a high frequency of visible intra-stent dissections by OCT, no inhospital events were registered. However, the long-term impact of the presence of vessel wall disruption in the stent segment in the incidence of restenosis or stent thrombosis is not known. The endothelial integrity is important to prevent thrombus deposition, and pathological examinations have associated stent thrombosis with the disruption of the vessel continuity and prolapse of the necrotic core between stent struts. ${ }^{21}$ Several animal and pathological studies have associated vessel injury with stent restenosis. ${ }^{1}{ }^{22}$ On the other hand, non-flow-limiting edge dissections detected by IVUS have not been associated with an increase in acute or long-term events such as restenosis but the impact of intra-stent dissections is not established. ${ }^{23-25}$ Furthermore, the location of a stent strut floating over an empty cavity without direct wall contact might also influence its coverage by tissue at follow-up. ${ }^{26}$

\section{Acute effects of stent implantation in stable versus unstable patients}

In our series, the frequency of tissue prolapse did not differ between stable and unstable patients but the tissue prolapse area was higher in the stable group. This result seems to be in contradiction with the concept of the underlying plaque type in stable and unstable patients. In theory, the plaque type in stable patients might be mainly fibrous while in unstable patients more lipid-rich and/or thrombosed plaques would be expected and those might be more prone to prolapse. However, to the best of our knowledge there are no reported data about differences in tissue prolapse between stable and unstable patients. Furthermore, pre-stent OCT examination was not performed in our sample and therefore no information is available about the underlying plaque type. No differences in the frequency of intra-stent or edge dissections were found between stable and unstable patients.

This study demonstrates the feasibility of a systematic classification and quantification of periprocedural vessel injury in vivo. This might allow the development of an injury score, analogous to the vascular injury score in histopathology, and may help to study vascular healing and to optimise stent design and implantation technique in the future. To date the reasons for stent failure (thrombosis and restenosis) are poorly understood and vessel trauma after stenting might be a missing link to help us improve our understanding of this important clinical problem. ${ }^{27} 28$

However, correlation with clinical events, both early and late, is required to determine whether these OCT observations have clinical significance, and this should be the aim of future studies. 
Table 4 Acute effects of stent implantation in the vessel wall in stable versus unstable patients

\begin{tabular}{|c|c|c|c|}
\hline Acute effects & Stable $(n=45)$ & Unstable $(n=35)$ & $\mathbf{p}$ \\
\hline \multicolumn{4}{|l|}{ Tissue prolapse } \\
\hline Tissue prolapse visible, $\mathrm{n}(\%)$ & $43 / 45(95.6)$ & $35 / 35(100)$ & 0.5 \\
\hline Number of sites of tissue prolapse, median (IOR) & $11(5-22)$ & $7(3-16)$ & 0.06 \\
\hline Number of sites of tissue prolapse per mm, median (IOR) & $0.42(0.22-0.80)$ & $0.26(0.14-0.44)$ & 0.047 \\
\hline Tissue prolapse area $\left(\mathrm{mm}^{2}\right)$, mean (SD) & $1.21(1.0)$ & $0.80(0.6)$ & 0.028 \\
\hline Tissue prolapse area per $\mathrm{mm}\left(\mathrm{mm}^{2}\right)$, mean (SD) & $0.04(0.03)$ & $0.03(0.02)$ & 0.03 \\
\hline Tissue prolapse average length $(\mu \mathrm{m})$, mean $(S D)$ & $147(43)$ & $157(40)$ & 0.2 \\
\hline Tissue prolapse maximum length $(\mu \mathrm{m})$, mean $(\mathrm{SD})$ & $260(95)$ & $247(85)$ & 0.5 \\
\hline \multicolumn{4}{|l|}{ Intra-stent dissection } \\
\hline Intra-stent dissection visible, $\mathrm{n}(\%)$ & $41 / 45(91.1)$ & $29 / 35(82.9)$ & 0.3 \\
\hline \multicolumn{4}{|l|}{ Intra-stent dissection flap } \\
\hline Intra-stent dissection flap visible, $\mathrm{n}(\%)$ & $39 / 45(86.7)$ & $30 / 35(85.7)$ & 0.9 \\
\hline Number of intra-stent dissection flaps, median (IQR) & $3(2-7)$ & $3(1-4)$ & 0.3 \\
\hline Number of intra-stent dissection flaps per mm, median (IQR) & $0.12(0.05-0.25)$ & $0.12(0.04-0.18)$ & 0.3 \\
\hline Intra-stent dissection flap average length $(\mu \mathrm{m})$, mean (SD) & $297(134)$ & $289(120)$ & 0.8 \\
\hline Intra-stent dissection flap maximum length $(\mu \mathrm{m})$, mean (SD) & $488(238)$ & $419(197)$ & 0.1 \\
\hline \multicolumn{4}{|l|}{ Intra-stent dissection cavity } \\
\hline Intra-stent dissection cavity visible, $\mathrm{n}(\%)$ & $32 / 45(71.1)$ & $23 / 35(65.7)$ & 0.6 \\
\hline Number cavities, median (IOR) & $2(0-4.5)$ & $1(0-5)$ & 0.6 \\
\hline Number cavities per mm, median (IQR) & $0.07(0-0.15)$ & $0.04(0-0.17)$ & 0.8 \\
\hline Maximum depth cavity $(\mu \mathrm{m})$, mean $(\mathrm{SD})$ & $336(183)$ & $357(150)$ & 0.6 \\
\hline \multicolumn{4}{|l|}{ Edge dissection } \\
\hline Edge dissection visible, $\mathrm{n}(\%)$ & $9 / 42(21.4)$ & $11 / 34(32.3)$ & 0.3 \\
\hline Edge dissection length $(\mu \mathrm{m})$, mean $(S D)$ & $860(579)$ & $650(277)$ & 0.3 \\
\hline
\end{tabular}

\section{Limitations}

The lack of clinical events during the study period does not allow a proper correlation of OCT-assessed vessel trauma with clinical outcome and it is the main limitation of the study. Intra-stent dissection and tissue prolapse were almost universal. Therefore identification of their presence alone has no significance. In order to find a more discriminatory OCT measure of vessel trauma we described different quantitative parameters for each type of post-stenting vessel injury. However, the lack of clinical events did not allow us to evaluate which parameter may be clinically significant. We assessed the acute effects of stent implantation visible by OCT and their clinical impact at short-term follow-up. Longterm follow-up studies including OCT imaging are needed in order to better define the clinical implications of these findings. The clinical presentation classification used has limitations as it included syndromes with different physiopathology (unstable angina/NSSTMI and STEMI) in the same group. However, owing to the limited sample size, it was not possible to divide the population into multiple subgroups. We acknowledge that the stent type might influence the vessel trauma observed by OCT. However, owing to the heterogeneity of the population, with different drug-eluting stents and a limited number of bare metal stents, no comparison between stent types was performed.

\section{CONCLUSIONS}

OCT allows for a detailed visualisation of periprocedural vessel wall trauma in coronary stenting and enables a systematic classification and quantification in vivo. In our study, the incidence of tissue prolapse or intra-stent dissections after stent implantation was high, irrespective of the clinical presentation of the patients, and was not associated with clinical events during the hospitalisation period.

Competing interests: None.

Patient consent: Obtained.

Provenance and peer review: Not commissioned; externally peer reviewed.

\section{REFERENCES}

1. Farb A, Sangiorgi G, Carter AJ, et al. Pathology of acute and chronic coronary stenting in humans. Circulation 1999;99:44-52.

2. Schwarzacher SP, Metz JA, Yock PG, et al. Vessel tearing at the edge of intracoronary stents detected with intravascular ultrasound imaging. Cathet Cardiovasc Diagn 1997; 40:152-5.

3. Gonzalo N, Serruys PW, Regar E. Optical coherence tomography: clinical applications and the evaluation of DES. Minerva Cardioangiol 2008;56:511-25.

4. Barlis P, Gonzalo N, Di Mario C, et al. A multi-centre evaluation of the safety of intracoronary optical coherence tomography. Eurointervention 2009;5:90-5

5. Gonzalo N, Garcia-Garcia HM, Regar E, et al. In vivo assessment of high-risk coronary plaques at bifurcations with combined intravascular ultrasound virtual histology and optical coherence tomography. JACC Cardiovasc Imaging 2009:2:473-82.

6. Gonzalo N, Ligthart J, Regar E. Tips and tricks for intravascular optical coherence tomography. In: Sabate, ed. Percutaneous interventions beyond stenting. Tips and tricks for new technology. Informa Healthcare (in press).

7. Bouma BE, Tearney GJ, Yabushita $\mathrm{H}$, et al. Evaluation of intracoronary stenting by intravascular optical coherence tomography. Heart 2003;89:317-20.

8. Gonzalo N, Barlis P, Serruys PW, et al. Incomplete stent apposition and delayed tissue coverage are more frequent in drug eluting stents implanted during primary percutaneous coronary intervention for ST elevation myocardial infarction than in drug eluting stents implanted for stable/unstable angina. Insights from optical coherence tomography. JACC Cardiovasc Interv 2009;2:445-52.

9. Takano M, Yamamoto M, Inami S, et al. Long-term follow-up evaluation after sirolimus-eluting stent implantation by optical coherence tomography: do uncovered struts persist? J Am Coll Cardiol 2008;51:968-9.

10. Chen BX, Ma FY, Luo W, et al. Neointimal coverage of bare-metal and sirolimuseluting stents evaluated with optical coherence tomography. Heart 2008;94:566-70.

11. Regar E, van Beusekom HMM, van der Giessen WJ, et al. Optical coherence tomography findings at 5-year follow-up after coronary stent implantation. Circulation 2005;112:345-6. 
12. Serruys PW, Ormiston JA, Onuma Y, et al. A bioabsorbable everolimus-eluting coronary stent system (ABSORB): 2-year outcomes and results from multiple imaging methods. Lancet 2009;373:897-910.

13. Diaz-Sandoval LJ, Bouma BE, Tearney GJ, et al. Optical coherence tomography as a tool for percutaneous coronary interventions. Catheter Cardiovasc Interv 2005;65:492-6.

14. Suzuki Y, Ikeno F, Yeung AC. Drug-eluting stent strut distribution: a comparison between Cypher and Taxus by optical coherence tomography. J Invasive Cardiol 2006; 18:111-4.

15. Kume T, Akasaka T, Kawamoto T, et al. Assessment of coronary arterial thrombus by optical coherence tomography. Am J Cardiol 2006;97:1713-7.

16. Takano M, Yamamoto M, Murakami D, et al. Optical coherence tomography after new scoring balloon angioplasty for in-stent restenosis and de novo coronary lesions. Int J Cardiol 2009 Jan 5. [Epub ahead of print].

17. Kim SW, Mintz GS, Ohlmann P, et al. Frequency and severity of plaque prolapse within Cypher and Taxus stents as determined by sequential intravascular ultrasound analysis. Am J Cardiol 2006;98:1206-11.

18. Jang IK, Tearney G, Bouma B. Visualization of tissue prolapse between coronary stent struts by optical coherence tomography: comparison with intravascular ultrasound. Circulation 2001:104:2754.

19. Hong MK, Park SW, Lee CW, et al. Long-term outcomes of minor plaque prolapsed within stents documented with intravascular ultrasound. Catheter Cardiovasc Interv 2000; $51: 22-6$
20. Futamatsu H, Sabate M, Angiolillo DJ, et al.Characterization of plaque prolapse after drug-eluting stent implantation in diabetic patients: a three-dimensional volumetric intravascular ultrasound outcome study. J Am Coll Cardiol 2006;48:1139-45.

21. Farb A, Burke AP, Kolodgie FD, et al. Pathological mechanisms of fatal late coronary stent thrombosis in humans. Circulation 2003;108:1701-6.

22. Schwartz RS, Huber KC, Murphy JG, et al. Restenosis and the proportional neointimal response to coronary artery injury: results in a porcine model. J Am Coll Cardiol 1992;19:267-74

23. Schroeder S, Baumbach A, Mahrholdt $\mathrm{H}$, et al. The impact of untreated coronary dissections on acute and long-term outcome after intravascular ultrasound guided PTCA. Eur Heart J 2000;21:137-45.

24. Hong MK, Park SW, Lee NH, et al. Long-term outcomes of minor dissection at the edge of stents detected with intravascular ultrasound. Am J Cardiol 2000;86:791-5, A799.

25. Sheris SJ, Canos MR, Weissman NJ. Natural history of intravascular ultrasound-detected edge dissections from coronary stent deployment. Am Heart J 2000;139:59-63.

26. Finn AV, Joner M, Nakazawa G, et al. Pathological correlates of late drug-eluting stent thrombosis: strut coverage as a marker of endothelialization. Circulation 2007:115:2435-41

27. Barlis $\mathbf{P}$, DiMario C, van Beusekom HMM, et al. Novelties in cardiac imaging - optical coherence tomography (OCT). A critical appraisal of the safety concerns tempering the success of drug-eluting stents. Eurointervention 2008;4(Suppl C):C22-6

28. Schinkel AFL, van Beusekom HM, Maugenest AM, et al. OCT findings in very late (4 years) paclitaxel-eluting stent thrombosis. JACC Cardiovasc Interv 2008;1:449-51. 


\section{HEART}

\section{Optical coherence tomography assessment of the acute effects of stent implantation on the vessel wall: a systematic quantitative approach}

N Gonzalo, P W Serruys, T Okamura, et al.

Heart 2009 95: 1913-1919 originally published online August 10, 2009 doi: $10.1136 /$ hrt.2009.172072

Updated information and services can be found at:

http://heart.bmj.com/content/95/23/1913.full.html

\section{These include:}

References This article cites 26 articles, 10 of which can be accessed free at: http://heart.bmj.com/content/95/23/1913.full.html\#ref-list-1

Article cited in:

http://heart.bmj.com/content/95/23/1913.full.html\#related-urls

Email alerting Receive free email alerts when new articles cite this article. Sign up in service the box at the top right corner of the online article.

Topic Articles on similar topics can be found in the following collections Collections

Notes

To request permissions go to:

http://group.bmj.com/group/rights-licensing/permissions

To order reprints go to:

http://journals.bmj.com/cgi/reprintform

To subscribe to BMJ go to:

http://group.bmj.com/subscribe/ 